\title{
Incidence of Cervical Human Papillomavirus and Cervical Intraepithelial Neoplasia in Women with Positive and Negative HIV Status
}

\section{Incidência de infecção cervical pelo vírus papiloma humano e neoplasia intraepitelial cervical em mulheres com sorologia positiva e negativa para o HIV}

\author{
Benito Pio Vitorio Ceccato Junior ${ }^{1}$ Mark Drew Crosland Guimarães ${ }^{2}$ Ana Paula Ceccato Lopes ${ }^{3}$ \\ Lorena Fiorini Nascimento $^{4}$ Luísa Magalhães Novaes ${ }^{3}$ Dora Méndez del Castillo ${ }^{5}$ Victor Hugo Melo ${ }^{6}$
}

${ }^{1}$ Department of Gynecology and Obstetrics, Faculdade de Ciencias Médicas de Minas Gerais - FCCMG, Belo Horizonte, Minas Gerais, Brazil

2 Department of Preventive and Social Medicine, Faculdade de Medicina, UFMG, Belo Horizonte, Minas Gerais, Brazil

3 Faculdade de Medicina de Barbacena, Barbacena, Minas Gerais, Brazil

${ }^{4}$ Faculdade de Ciencias Médicas de Minas Gerais - FCCMG, Belo

Horizonte, Minas Gerais, Brazil

${ }^{5}$ Center for Action and Research in Support Diagnostics, UFMG, Belo Horizonte, Minas Gerais, Brazil

6 Department of Gynecology and Obstetrics, Faculdade de Medicina, Universidade Federal de Minas Gerais - UFMG, Belo Horizonte, Minas Gerais, Brazil

Rev Bras Ginecol Obstet 2016;38:231-238.
Address for correspondence Victor Hugo Melo, DSc, Department of Obstetrics and Gynecology, Faculdade de Medicina, Universidade Federal de Minas Gerais - UFMG, Avenida Alfredo Balena, 190, 30130100-Belo Horizonte, MG, Brazil (e-mail: victormelo@terra.com.br).

\begin{abstract}
Keywords

- HIV infections

- HPV DNA probes

- papillomavirus infections

- cervical intraepithelial neoplasia

- polymerase chain reaction
\end{abstract}

Objectives To evaluate the incidence and factors associated with cervical intraepithelial neoplasia (CIN) and cervical infection by human papillomavirus (HPV) among HIV-positive and HIV-negative women.

Methods A cohort of 103 HIV positive and 113 HIV negative women were monitored between October 2008 and February 2012, for at least one year. Procedures included cervical cytology, DNA/HPV detection by polymerase chain reaction, colposcopy with biopsy if necessary, followed by an interview for exposure characteristics data. CIN was based on the histopathological results.

Results The incidence of CIN was of 8.8 and 4.6 cases/100 women-years in HIVpositive and HIV-negative women, respectively. HIV-positive women presented a hazard ratio (HR) of 2.8 for CIN and developed lesions earlier ( 0.86 year) than HIVnegative women (2 years) $(p=0.01)$. The risk of developing CIN decreased with age $(H R=0.9)$ and marital status $(H R=0.4)$. HPV patients presented a higher incidence of CIN when compared HIV-positive and HIV-negative women $(p=0.01)$. The incidence of HPV cervical infection was 18.1 and 11.4 cases/100 women-years in HIV-positive and HIV-negative women, respectively. Those HIV-positive presented earlier HPV infection $(p=0.002)$. The risk of developing HPV infection decreased with age and was higher received

November 25, 2015

accepted

February 2, 2016

published online

April 28, 2016
DOI http://dx.doi.org/

10.1055/s-0036-1583294. ISSN 0100-7203.
Copyright $(\underset{0}{ } 2016$ by Thieme Publicações License terms

Ltda, Rio de Janeiro, Brazil
(요 (1) $\Theta \circledast$ 


\section{Resumo}

\section{Palavras-chave}

- infecções por HIV

- sondas de DNA de HPV

- infecções por papillomavirus

- neoplasia intraepitelial cervical

- reação em cadeia da polimerase among HIV-positive women. HPV 16 was the most common type in HIV-positive women, and also the type most closely associated with CIN in HIV-negative women. Conclusions HIV-positive women had a greater incidence of HPV and CIN, and in a shorter time interval. More rigorous and timely clinical control is required for this group.

Objetivos Avaliar a incidência e fatores associados com neoplasia intraepitelial cervical (NIC) e infecção cervical pelo Papiloma Vírus Humano (HPV) entre mulheres HIV positivas e negativas.

Métodos Coorte de 103 mulheres positivas para o HIV e 113 negativas, que foram acompanhadas entre outubro de 2008 a fevereiro de 2012, com seguimento mínimo de um ano. Os procedimentos realizados foram coleta de material cervical para citologia oncótica e detecção do DNA/HPV pela reação em cadeia da polimerase, colposcopia seguida de biópsia, se necessário, e entrevista para obter dados e características de exposição. O diagnóstico de NIC foi baseado no resultado histopatológico das biópsias.

Resultados A incidência pessoas-tempo de NIC foi de 8,8 e 4,6 casos/100 mulheresano para as mulheres HIV-positivas e HIV-negativas, respectivamente. As HIV-positivas apresentaram uma razão de risco (HR) de 2,8 para NIC e desenvolveram lesões mais precocemente $(0,86$ ano) do que as negativas $(2$ anos) $(p=0,01)$. O risco de desenvolver NIC diminuiu com a idade $(H R=0,9)$ e o estado civil $(H R=0,4)$. Pacientes com HPV apresentaram maior incidência de NIC, quando comparadas as mulheres HIVpositivas e as negativas $(47,6 \times 10,5 \%)(p=0,01)$. A incidência de infecção cervical pelo HPV, por pessoa/tempo, foi de 18,1 e 11,4 casos/100 mulheres-ano, respectivamente para mulheres HIV-positivas e negativas. As HIV-positivas apresentaram HPV mais precocemente $(p=0,002)$. O risco de apresentar HPV diminuiu com a idade e foi maior entre as HIV-positivas. O HPV 16 foi o tipo mais comum entre as mulheres HIVpositivas.

Conclusões As mulheres HIV-positivas tiveram maior incidência de HPV e NIC, e um menor intervalo de tempo. Controle clínico mais rigoroso e oportuno é requerido para este grupo.

\section{Introduction}

Cervical cancer is the second most frequent tumor in the Brazilian female population (8.1\%) after breast cancer (20.6\%), and is the fourth leading cause of cancer death in women in Brazil. This type of cancer is associated with infection by HPV, and some of its subtypes entail a high risk for malignant tumors. ${ }^{1}$

HPV infection is considered the most prevalent sexually transmitted disease (STD) in the world. ${ }^{2}$ The relationship between cervical cancer and HPV infection is well established, and high-risk HPV has been detected in almost all cases of cervical cancer. ${ }^{3}$ Neoplastic transformation is mediated by the action of HPV, and is a direct consequence of viral infection. ${ }^{4}$ The persistent infection by high-risk HPV is a strong predictor of risk for CIN. ${ }^{5}$ Meta-analysis have demonstrated that HPV 16 is the most prevalent type, followed by type 18 , and both types are responsible for $65.9 \%$ of all cases of cervical cancer. ${ }^{3}$

HPV infection is an essential factor for the development of cervical cancer but is not sufficient; the risk of acquiring cervical infection by HPV during one's lifetime is $84 \%$, but the incidence of cervical cancer is only $0.7 \%{ }^{6}$ Other risk factors, including immune factors, co-infection with HIV and STDs, as well as behavioral factors, such as the early initiation of sexual life, multiple sex partners and smoking, may explain the progress of these infections. ${ }^{6,7}$

HIV-positive women have a higher risk of acquiring cervical infection by HPV, and those co-infected with HPV have a greater chance of developing CIN, probably because of low immunity. Cohort studies have shown that the incidence of cervical lesions varied between 4.9 and $9 \%$ in HIV-negative women, and between 20 and 35\% in HIV-positive women. ${ }^{8,9}$

A meta-analysis of 15 studies has shown that cervical infections by HPV and HIV were factors independently associated with cervical cancer. The interaction between HPV, HIV and the development of cervical cancer has also been demonstrated. Immunosuppression was not associated with cervical disease. The conclusion was that HIV seems to be a risk cofactor in the association between infection by HPV and $\mathrm{CIN}^{10} \mathrm{~A}$ recent study has demonstrated that the most 
important factor for contracting an HPV infection was coinfection with HIV. ${ }^{11}$

The present study aims to evaluate and compare the incidence of CIN and cervical infection by HPV among HIV-positive and HIV-negative women. The HPV types and their correlation with the development of CIN and the factors that influenced these diseases were also evaluated.

\section{Methods}

A prospective cohort of HIV-positive or HIV-negative women was monitored in two public medical care referral centers in Belo Horizonte, Brazil, between 2006 and 2011. The study was approved by the Ethical Review Boards of all the institutions involved (Universidade Federal de Minas Gerais UFMG, under Opinion No. 289 ETIC/2008 and Faculdade de Ciências Médicas de Minas Gerais - FCMMG, under Research Protocol No. 87/2007).

\section{Population}

Two groups of women were monitored according to their HIV status (positive or negative). Non-pregnant women over 18 years old and without CIN at the first consultation were included in the two groups. The absence of CIN was defined as uterine cervix without cervical intraepithelial lesion upon smear cytology and with normal colposcopy, or as negative biopsy for CIN, when performed. Hysterectomized women were excluded. All patients signed a free informed consent form.

HIV-negative women were selected HIV-negative women were selected on routine first-come first-served basis at FCMMG Affonso Silvianao Brandão Outpatient Service with enrollment between October 2008 and February 2011. HIVpositive women were selected at the Gynecology Outpatient Service of the Clinical Hospital of UFMG between October 2006 and February 2011. All participants had a minimum follow-up of one year, until February 2011 or until the occurrence of any events, and the intervals between consultations ranged between six months and one year.

Similarly, HIV positive women were recruited on a routine first-come first-served basis, regardless of antirretroviral use, clinical stage of infection, or morbidities that might have appeared before or during the study period.

\section{Events and Data Collection}

An event was defined as the occurrence of CIN and/or cervical infection by HPV. In all consultations, a gynecological examination was performed, as well as the collection of material for cervical cytology and confirmation of cervical infection by HPV. After the collection, colposcopy was performed. Directed biopsies were performed for all colposcopy changes visualized. Participants were asked to answer a standardized questionnaire on demographic and behavioral data in the first and subsequent consultations, and to assess their correlation with the occurrence of events. There was no interruption of the follow-up with the occurrence of a single event, and two events did not occur simultaneously during the study period.

The occurrence of CIN was defined according to the result of the histopathological examination of the biopsies of the colposcopy alterations identified during the gynecological examination and it was based on Richart's Classification.

The occurrence of cervical infection by HPV was defined by the detection of cervical HPV in women with previous negative diagnosis. All patients underwent the same method for detection and typing of HPV. Initially, HPV was detected via PCR using a nested-PCR strategy. Subsequently, the amplification product of the nested-PCR was sequenced directly. The samples were purified and sequenced using the BigDye Terminator kit (version 3.1; Byosystems, Foster City, USA) and the GP6+ primer set. The sequences were analyzed in an ABI Prism 3100-Avant genetic analyzer (Byosystems, Foster City, USA). The sequences obtained were edited by selecting 30 nucleotide segments and aligning them with HPV sequences retrieved from the ICTVdB database using the Bioedit software version 7.0, Carlsbad, USA. ${ }^{12}$ In cases in which this technique identified the presence of two or more viral types, PCR was performed for the other 11 frequent types in our region $(6,11,16,18,31,33,35,39,45,56$ and 58). HPV was detected by PCR with a nested-PCR approach using the MY09/11 and GP5 $+16+$ primer sets. ${ }^{12}$ The combination of the two methods had a sensitivity of $87 \%$ for the identification of typespecific HPV, which was higher than the sensitivity of PCR and sequencing alone (36 and $75 \%$ respectively), indicating that the two methods are complementary. ${ }^{12}$

The presence of cervical HPV was assessed in the first and in all subsequent consultations. The occurrence of cervical infection by HPV was defined by the detection of cervical HPV by PCR. Inhibition of the amplification of HPV DNA was assessed by inhibition of the amplification of the human globin gene by viral DNA. In these cases, it was not possible to evaluate the presence of HPV. Based on the available published data, the following viral types were considered as high-risk HPV: 16, 18, 31, 33, 35, 39, 45, 51, 52, 53, 55, 56, 58, $59,66,67,68,69,70,73,82$ and $83 .^{13,14}$

HHIV-negative women were assessed for HIV status shift and only those who remained HIV negative throughout the study period were kept in this group until the end of the study or the appearance of the events of interest (such as HPV and CIN). There were no cases of serologic shift in this sample. HIV-positive women had previously confirmatory HIV diagnosis according to the standard Ministry of Health Protocol adopted in Brazil at the time of the study. ${ }^{15}$

The following sociodemographic and behavioral data possibly involved in the development of CIN and cervical infection by HPV were collected: age; marital status (stable and unstable relationships); age at first sexual intercourse; education (number of years of regular schooling); number of pregnancies, deliveries, and abortions; number of sexual partners (stratified into lower or higher than 3 ); number of sexual partners in the past year (stratified as without a partner or with 1 or more partners); smoking status (yes or no); type of employment (from home or working outside of home); and use of condom as a contraceptive (yes or no).

The sample size was calculated using the methodology proposed for the analysis of longitudinal studies ${ }^{16}$ based on published data which included a prevalence of CIN of $8 \%$ and a relative risk of 4.5 for HIV-positive women. ${ }^{8}$ Considering a significance level of $5 \%$ and power of $90 \%$, a sample of 60 
women would be required in each group, totaling 120 patients.

\section{Statistical Analysis}

An initial descriptive analysis was conducted to assess sociodemographic characteristics and data consistency. Statistical significance of categorial variables was assessed by Pearson Chi-square $\left(\chi^{2}\right)$ test while for continuous variables Student's t-test was used. The cumulative incidence of CIN or cervical infection by HPV was calculated by dividing the number of new cases of CIN or HPV by the total number of women who had not yet develop CIN or cervical infection by HPV. Personyear incidence of CIN or cervical infection by HPV was calculated by dividing the number of new cases by the sum of the periods of risk for each of these two events. Kaplan-Meier analysis was used to estimate the median time of onset of CIN and cervical infection with HPV, and the logrank test was used to compare the curves for the two groups. Cox proportional hazards model was used in the univariate and multivariate analysis to identify factors associated with the incidence of HPV and CIN. The magnitude of the associations was estimated using the Hazard Ratio (HR) with 95\% confidence interval $(95 \% \mathrm{CI})$. Predictive variables with a $p$-value $<0.15$ in the univariate analysis were selected for inclusion in the multivariate model. Cox multivariate regression was adjusted using the backward algorithm and only variables with $p$-value $<0.05$ remained in final models. The software used in the analysis was $R$ version 2.13.0.

\section{Results}

The present study is part of a cohort study aimed at determining the incidence of CIN and cervical infection by HPV. Among the HIV-positive women, 63.7\% used antiretroviral drugs.

The incidence of CIN was evaluated in 103 HIV-positive women and 113 HIV-negative women, and none of the women evaluated presented CIN in the first consultation and were monitored for at least one year. The overall cumulative incidence of CIN was 8.0\% in HIV-negative women (9 of 113) and $17.4 \%$ in HIV-positive women (18 of 103) $(p=0.08)$. The incidence of CIN was 4.6 and 8.8 cases/100 person-years for the HIV-positive and HIV-negative women, respectively. Overall, CIN was detected in $10 \%$ of the cases after 0.86 year and 2.03 years of follow-up for, respectively, HIV-positive and HIVnegative women $(p=0.01)$ ( $\mathbf{- F i g . 1}$ ).

The univariate analysis $(p<0.15)$ included potential predictors. The univariate analysis $(p<0.15)$ included potential

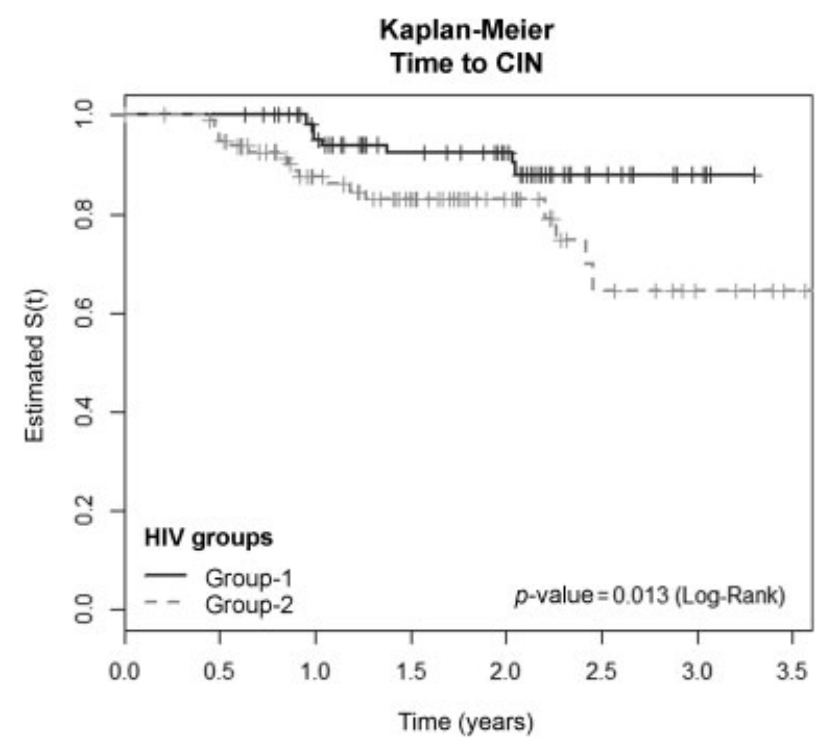

Fig. 1 Kaplan-Meier model for the time of progression to CIN (group 1, HIV-negative women; group 2, HIV-positive women).

predictors of CIN in the multivariate regression model: infection by HIV (HIV-positive patients presented a higher risk of developing CIN than those HIV-negative); age (the incidence of CIN decreased for every year of life and every year after the initiation of sexual life); marital status (those who were married or in a stable relationship had a lower risk of developing CIN than single, separated and divorced women).

Cox multivariate analysis indicated that the risk of developing CIN was higher among HIV-positive women $(\mathrm{HR}=2.9$; 95\% CI: 1.27-6.55) and in younger women (decreased $~ 5.0 \%$ for each year of life; $\mathrm{HR}=0.95 ; 95 \% \mathrm{CI}$ : 0.91-0.98), and was lower in women in a stable relationship $(\mathrm{HR}=0.4 ; 95 \% \mathrm{CI}$ : 0.18-0.91) (-Table 1).

To evaluate the incidence of cervical HPV infection, 70 HIV-positive and 93 HIV-negative women were assessed and monitored for at least one year. Women with cervical infection by HPV in the first consultation and those whose amplification reactions were inconclusive were excluded from this analysis. During the entire study period, 58 inconclusive reactions were identified (35 in HIV-negative and 23 in HIV-positive women) and were thus excluded. Moreover, one sample was inappropriate and it was therefore discarded. The overall cumulative incidence of cervical infection by HPV was $19.4 \%$ in HIV-negative women (18 of 93 ) and $18.5 \%$ in HIV-positive women (13 of 70$)(p=0.899)$. The

Table 1 Cox multivariate analysis of the time of progression to CIN according to HIV status, sociodemographic factors, sexual behavior, and possible progression factors

\begin{tabular}{|l|l|l|l|l|}
\hline Variables & P-Value & HR & $95 \% \mathrm{Cl}$ & \\
\hline HIV-positive & 0.01 & 2.88 & $1.27-$ & 6.55 \\
\hline Age & 0.01 & 0.96 & $0.91-$ & 0.98 \\
\hline Marital status - stable relationship & 0.03 & 0.41 & $0.18-$ & 0.91 \\
\hline
\end{tabular}

Abbreviations: $\mathrm{HR}$, hazard risk; $\mathrm{Cl}$, confidence interval. 


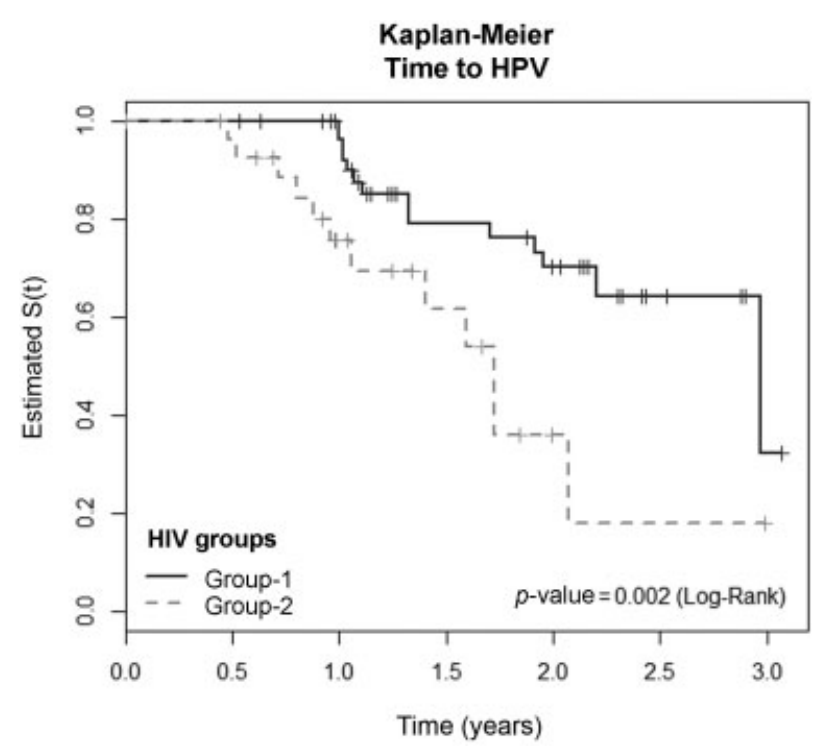

Fig. 2 Kaplan-Meier models for the time of progression to HPV infection (group 1, HIV-negative women; group 2, HIV-positive women).

incidence of cervical infection by HPV was of 11.4 and 18.1 cases/100 person-years among HIV-positive and HIV-negative women, respectively. The median time of onset of cervical infection by HPV was $\sim 1.65$ years for the seropositive patients and 2.6 years for the seronegative patients $(p=0.002)$ (-Fig. 2).

The univariate analysis $(p<0.15)$ included potential predictors of the presence of HPV in the multivariate regression model: infection by HIV (HIV-positive patients had a higher risk of contracting HPV than HIV-negative patients) and age (the incidence of cervical infection by HPV decreased for every year of life and for every year after the initiation of sexual life).

Cox multivariate analysis indicated that the risk of cervical infection by HPV was higher among HIV-positive women ( $\mathrm{HR}=2.1 ; 95 \% \mathrm{CI}: 1.02-4.93)$, and among younger women the risk decreased $17.2 \%$ for each year after the initiation of sexual life ( $\mathrm{HR}=0.8 ; 95 \% \mathrm{CI}$ : 0.73-0.93) (-Table 2).

A total of 34 different types of HPV were detected in this study in the two study groups, 16 of which were high-risk types. HIV-positive women had a higher incidence of CIN, and those who developed CIN had a higher incidence of cervical infection by HPV; accordingly, the incidence of the latter was 47.8 and $10.5 \%(p=0.015)$ in HIV-positive and
HIV-negative women, respectively. Furthermore, HIV-positive women had a higher incidence of cervical infection by high-risk HPV than HIV-negative women (14.9 and 7.9\% respectively), although this difference was not statistically significant ( $p=0.127$ ). HPV type 16 was the type with the highest incidence in both groups: 9.2 and 5.9\% of the total cases of cervical infection in HIV-positive and HIV-negative women, respectively.

\section{Discussion}

The overall incidence of CIN in this study was high and it was higher among HIV-positive women. These results differ from those in the literature, possibly because of differences in methodology. One study that used a similar methodology, that is, biopsy directed by colposcopy for the diagnosis of CIN, found rates of 5 and $20 \%$ for HIV-positive and HIVnegative women, respectively, ${ }^{8}$ which were similar to our results of 8.0 and $15.5 \%$ respectively. Other studies revealed results of 9 and $35 \%{ }^{10}$ and of 2.7 and $4.9 \% .{ }^{17}$ However, these studies only used smear cytology in the diagnosis of CIN. Of the two studies that included only HIV-positive women, one of them found a cumulative incidence of $13.5 \%$ with a mean follow-up of 40 months, ${ }^{18}$ which is similar to our results, whereas the authors of the other study did not find any new case of CIN after 12 months of follow-up. ${ }^{19}$ A more recent cohort study showed that for high-grade lesions (CIN 2 and 3) the incidence was also higher in HIV-positive than in HIVnegative women (12 and 4\% for CIN 2 and 5 and $2 \%$ for CIN 3 respectively). ${ }^{20}$

The cumulative incidence of CIN in our study was 4.6 and 8.8/ 100 women-years for HIV-positive and HIV-negative women, respectively. Other studies with different methodologies found rates of 2.6 and 11.5 person-years (using only diagnostic cytology) 20 and 1.5 and 15.1 person-years (using cytology for screening, and colposcopy followed by biopsy of the cytological alterations). ${ }^{21}$ Another study performed in HIV-positive women revealed an incidence of 4.1 person-years. ${ }^{18}$

In the present study, HIV-positive women developed CIN in a shorter interval than HIV-negative women (0.9 and 2 years respectively), and presented a relative risk (RR) of 2.9 , whereas other authors found a relative risk (RR) of 4.5 for the development of CIN among HIV-positive women. ${ }^{10}$

The data on the cumulative incidence of cervical infection by HPV in HIV-positive and HIV-negative women are diverse: 73.4 and $90.2 \%,{ }^{22} 55.0$ and $80 \%,{ }^{23}$ and 32 and $54 \%{ }^{24}$ for HIVnegative and HIV-positive women respectively, and one

Table 2 Cox multivariate analysis of the presence of cervical infection by HPV according to HIV status, sociodemographic factors, sexual behavior, and possible progression factors

\begin{tabular}{|l|l|l|l|}
\hline Variables & P-Value & HR & 95\% CI \\
\hline HIV-positive & 0.04 & 2.12 & $1.02-4,93$ \\
\hline Initiation of sexual life & 0.01 & 0.82 & $0.73-0.93$ \\
\hline
\end{tabular}

Abbreviations: $\mathrm{HR}$, hazard risk; $\mathrm{Cl}$, confidence interval. 
study did not find any new case of cervical infection by HPV in HIV-positive women after 12 months of follow-up. ${ }^{19}$ Our results indicated an incidence of 19.5 and $18.5 \%$ for HIVpositive and HIV-negative women, respectively. The differences found in the literature for HIV-positive and HIVnegative women may be related to the selection criteria of patients: the HIV-negative women selected in this study had a healthy sexual behavior, whereas other studies recruited HIV-negative women with a risky sexual behavior, who are known to be more prone to infection by HPV and other STDs. ${ }^{8,9,25,26}$ Another factor that may have interfered with the results is the average period of enrollment in the study, because the longer the follow-up period, the higher the exposure and the probability of acquiring an HPV infection. The follow-up period ranged between $1.0^{19}$ and 5.5 years $^{27}$ in previous studies, and it was of 1.6 years in the present study.

HIV-positive women presented a higher incidence of cervical infection by low and high-risk HPV, ${ }^{24,28}$ and HPV type 16 had the strongest association with the development of CIN. ${ }^{5,6,8,23,26,29}$ Cervical infection with HPV and infection persistence were associated with the development of CIN, and infection by types 16 and 18 was associated with higher risk. ${ }^{8}$ Other studies also showed that HPV types 16 and 18 were strongly associated with the persistence and progression of cervical lesions compared with other high-risk types. ${ }^{5,6}$ In this study, 34 types of HPV were identified, 16 of which presented the highest risk. The incidence of cervical infection by high-risk HPV and by CIN was higher in HIV-positive women; in addition, the incidence of HPV 16 was higher in the two study groups, with a rate of $9.2 \%$ and $5.9 \%$ in HIV-positive and HIV-negative women respectively.

Genital infections with HPV and CIN are associated with risky sexual behaviors, number of sexual partners and age at first sexual intercourse, ${ }^{30}$ and younger age and a higher number of sexual partners were the main risk factors. ${ }^{8,31}$ Younger women tend to have a higher number of sexual partners. ${ }^{29,32}$ In the present study, women with positive serology for HIV had RR of 2.9 and 2.2 for cervical infection by HPV and CIN, respectively. Among the demographic and behavioral factors analyzed, those that influenced the development of CIN were age (younger women had a higher risk, and this risk declined by $4.8 \%$ for each year of life) and the marital status of women in stable relationships, such as younger women, and those who were not in stable relationships had a higher risk of developing CIN. Age significantly influenced cervical infection by HPV, such that younger women had a higher risk of infection, and this probability decreased $\sim 18 \%$ for every year after the beginning of sexual life.

The limitations of this study include the fact that the selected women did not represent the general population. HIV-negative women with low socioeconomic status from various regions of Belo Horizonte and satellite cities were recruited on a first-come, first-served basis at a gynecology outpatient clinic; they all had a low risk for cervical infection by HPV and CIN. The women infected with HIV were part of a cohort of women monitored in a referral medical care facility. Another limitation was the large number of losses. Several women did not attend the scheduled appointments, despite attempts to contact them. Because no remuneration was provided, many may have missed their appointments due to financial hardship or because they could not be absent from work. Strategies such as the donation of transportation coupons and the justification of absences at work could minimize these losses. Although the rate of losses was high (28.7 and 34.6\% for HIV-positive and HIV-negative women respectively), they were similar to those reported in the literature (between 22 and 35\%). ${ }^{31-33}$

On the other hand, one of the strengths of this study was the performance of colposcopy in all consultations, with directed biopsies of the colposcopy alterations when necessary; this allowed the histopathological study of the uterine cervix, which is the gold standard for the diagnosis of neoplastic cervical changes. Colposcopy had a good agreement (92\%) with the results of the biopsy when a degree of difference between the histological interpretations of CIN 2 and 3 in situ was allowed. ${ }^{33}$ Another strength of our study is that a large part of the cohort studies published used the smear cytology for diagnosis of squamous intraepithelial lesion (SIL) and/or used colposcopy with directed biopsy only when alterations in smear cytology were observed. Some authors have indicated that screening methods for cervix cancer based on cytology are currently recognized as ineffective because of their low sensitivity, and that other screening techniques are desirable. ${ }^{34}$ A meta-analysis compared smear cytology and the DNA test for HPV and found that cytology presented a low sensitivity, with a high incidence of cancer in apparently well-screened women. ${ }^{35}$ In our study, the sensitivity of smear cytology for the diagnosis of CIN was of $46.7 \%$. One should note that because of antiretroviral therapy, data of viral and CD4 cell count in the progression to CIN and cervical infection by HPV were only available among HIV-positive women, and no comparison was carried out for these variables.

The results found in this study highlight the need to reassess the effectiveness of screening for cervical cancer exclusively via smear cytology. We believe that the possibility of diagnosing cervical infections according to high-risk HPV due to its strong association with cervical cancer precursor lesions should be considered. Women with highrisk HPV should have an annual colposcopy assessment with biopsy of suspicious lesions. HIV-positive women who harbor high-risk HPV due to their higher risk of developing CIN should have this control (colposcopy with biopsy of the suspected lesions) every six months for two years, with annual monitoring after this period when lesions are absent.

We conclude that HIV-positive women have a greater incidence of CIN, and CIN lesions developed in a shorter interval. In addition, younger women and those who are not in a stable relationship have a higher chance of developing CIN. The incidence of cervical infection by HPV was similar between the two study groups; however, the presence of the virus was detected earlier in HIV-positive women. Younger women had a higher chance of developing cervical infection by HPV. HPV type 16 presented the highest risk, and its 
incidence was higher and closely associated with the development of CIN in both groups.

\section{Acknowledgments}

We are grateful to the Research Support Foundation of Minas Gerais (FAPEMIG) and the National Council for Scientific and Technological Development (CNPq) for the financial support.

\section{References}

1 Brasil. Ministério da Saúde. Instituto Nacional de Câncer José Alencar Gomes da Silva [Internet]. Estimativa 2012: incidência de câncer no Brasil. Rio de Janeiro: INCA; 2011 [citado 2012 Aug 21]. Disponível em: http://portal.saude.sp.gov.br/resources/ses/perfil/gestor/homepage/estimativas-de-incidencia-de-cancer-2012/ estimativas_incidencia_cancer_2012.pdf

2 Roccio M, Dal Bello B, Gardella B, et al. HPV infection and intraepithelial lesions: comparison between HIV positive and negative women. Curr HIV Res 2012;10(7):614-619

3 Tricco AC, Ng CH, Gilca V, Anonychuk A, Pham B, Berliner S. Canadian oncogenic human papillomavirus cervical infection prevalence: systematic review and meta-analysis. BMC Infect Dis 2011;11:235

4 zur Hausen H. Papillomaviruses in the causation of human cancers - a brief historical account. Virology 2009;384(2): 260-265

5 Trottier H, Mahmud SM, Lindsay L, et al; GSK HPV-001 Vaccine Study Group. Persistence of an incident human papillomavirus infection and timing of cervical lesions in previously unexposed young women. Cancer Epidemiol Biomarkers Prev 2009;18(3): $854-862$

6 Thomison J III, Thomas LK, Shroyer KR. Human papillomavirus: molecular and cytologic/histologic aspects related to cervical intraepithelial neoplasia and carcinoma. Hum Pathol 2008; 39(2):154-166

7 Kirwan JM, Herrington CS. Human papillomavirus and cervical cancer: where are we now? BJOG 2001;108(12):1204-1213

8 Ellerbrock TV, Chiasson MA, Bush TJ, et al. Incidence of cervical squamous intraepithelial lesions in HIV-infected women. JAMA 2000;283(8):1031-1037

9 Six C, Heard I, Bergeron C, et al. Comparative prevalence, incidence and short-term prognosis of cervical squamous intraepithelial lesions amongst HIV-positive and HIV-negative women. AIDS 1998;12(9):1047-1056

10 Mandelblatt JS, Kanetsky P, Eggert L, Gold K. Is HIV infection a cofactor for cervical squamous cell neoplasia? Cancer Epidemiol Biomarkers Prev 1999;8(1):97-106

11 Hessol NA, Holly EA, Efird JT, et al. Concomitant anal and cervical human papillomavirusV infections and intraepithelial neoplasia in HIV-infected and uninfected women. AIDS 2013;27(11): 1743-1751

12 Carvalho NO, del Castillo DM, Perone C, Januário JN, Melo VH, Brasileiro Filho G. Comparison of HPV genotyping by typespecific PCR and sequencing. Mem Inst Oswaldo Cruz 2010; 105(1):73-78

13 Fuessel Haws AL, He Q Rady PL, et al. Nested PCR with the PGMY09/11 and GP5 $(+) / 6(+)$ primer sets improves detection of HPV DNA in cervical samples. J Virol Methods 2004;122(1): 87-93

14 Weaver B, Shew M, Qadadri B, et al. Natural history of multiple human papillomavirus infections in female adolescents with prolonged follow-up. J Adolesc Health 2011;48(5):473-480
15 Brasil. Ministério da Saúde. Secretaria de Vigilância em Saúde [Internet]. Portaria n. 151, de 14 de outubro de 2009. 2009 [citado 2013 Abr. 10]. Disponível em: http://bvsms.saude.gov.br/bvs/ saudelegis/svs/2009/prt0151_14_10_2009.html

16 Diggle PJ, Heagerty PJ, Liang K, Zeger SL. Analysis of longitudinal data. 2nd ed. Oxford: Oxford University Press; 2002

17 Araújo AC, Carvalho NO, Teixeira NC, et al. Incidence of cervical intraepithelial neoplasia in a cohort of HIV-infected women. Int J Gynaecol Obstet 2012;117(3):211-216

18 Isaakidis P, Pimple S, Varghese B, et al. HPV infection, cervical abnormalities, and cancer in HIV-infected women in Mumbai, India: 12-month follow-up. Int J Womens Health 2013; 5:487-494

19 Schuman P, Ohmit SE, Klein RS, et al; HIV Epidemiology Research Study (HERS) Group. Longitudinal study of cervical squamous intraepithelial lesions in human immunodeficiency virus (HIV)seropositive and at-risk HIV-seronegative women. J Infect Dis 2003;188(1):128-136

20 Massad LS, Xie X, D'Souza G, et al. Incidence of cervical precancers among HIV-seropositive women. Am J Obstet Gynecol 2015; 212(5):606.e1-606.e8

21 Singh N, Bansal B, Singh U, Qureshi S, Tripathi AK. Comparative study of preinvasive and invasive lesions of the cervix in HIV-positive and HIVnegative women. Clin Cancer Invest J. 2015;4(1):39-42

22 Branca M, Rossi E, Alderisio M, et al. Performance of cytology and colposcopy in diagnosis of cervical intraepithelial neoplasia (CIN) in HIV-positive and HIV-negative women. Cytopathology 2001; 12(2):84-93

23 Strickler HD, Burk RD, Fazzari M, et al. Natural history and possible reactivation of human papillomavirus in human immunodeficiency virus-positive women. J Natl Cancer Inst 2005; 97(8):577-586

24 Ahdieh L, Klein RS, Burk R, et al. Prevalence, incidence, and typespecific persistence of human papillomavirus in human immunodeficiency virus (HIV)-positive and HIV-negative women. J Infect Dis 2001;184(6):682-690

25 Ng'andwe C, Lowe JJ, Richards PJ, Hause L, Wood C, Angeletti PC. The distribution of sexually-transmitted Human Papillomaviruses in HIV positive and negative patients in Zambia, Africa. BMC Infect Dis 2007;7:77

26 Almonte M, Silva IdosS, Asare A, et al. Sexual behavior and HPV infection in British women, by postal questionnaires and telephone interviews. J Med Virol 2011;83(7):1238-1246

27 Giuliano AR, Harris R, Sedjo RL, et al. Incidence, prevalence, and clearance of type-specific human papillomavirus infections: The Young Women's Health Study. J Infect Dis 2002; 186(4):462-469

28 Vaccarella S, Franceschi S, Herrero R, et al; IARC HPV Prevalence Surveys Study Group. Sexual behavior, condom use, and human papillomavirus: pooled analysis of the IARC human papillomavirus prevalence surveys. Cancer Epidemiol Biomarkers Prev 2006; 15(2):326-333

29 Minkoff H, Feldman J, DeHovitz J, Landesman S, Burk R. A longitudinal study of human papillomavirus carriage in human immunodeficiency virus-infected and human immunodeficiency virus-uninfected women. Am J Obstet Gynecol 1998;178(5): 982-986

30 Nielsen A, Iftner T, Munk C, Kjaer SK. Acquisition of highrisk human papillomavirus infection in a population-based cohort of Danish women. Sex Transm Dis 2009;36(10): 609-615

31 Franco EL, Villa LL, Sobrinho JP, et al. Epidemiology of acquisition and clearance of cervical human papillomavirus infection in women from a high-risk area for cervical cancer. J Infect Dis 1999;180(5):1415-1423

32 Derchain SF, Sarian LO, Naud P, et al. Safety of screening with Human papillomavirus testing for cervical cancer at three-year 
Ceccato Júnior et al.

intervals in a high-risk population: experience from the LAMS study. J Med Screen 2008;15(2):97-104

33 Stoler MH, Vichnin MD, Ferenczy A, et al; FUTURE I, II and III Investigators. The accuracy of colposcopic biopsy: analyses from the placebo arm of the Gardasil clinical trials. Int J Cancer 2011; 128(6):1354-1362

34 Castle PE, Stoler MH, Wright TC Jr, Sharma A, Wright TL, Behrens CM. Performance of carcinogenic human papilloma- virus (HPV) testing and HPV16 or HPV18 genotyping for cervical cancer screening of women aged 25 years and older: a subanalysis of the ATHENA study. Lancet Oncol 2011;12(9): 880-890

35 Cuzick J, Clavel C, Petry KU, et al. Overview of the European and North American studies on HPV testing in primary cervical cancer screening. Int J Cancer 2006;119(5): 1095-1101 